\title{
A unique method for culturing diatoms on agar plates
}

\author{
Kei Kimura ${ }^{1,2} \&$ YujI Tomaru ${ }^{1, *}$ \\ ${ }^{1}$ National Research Institute of Fisheries and Environment of Inland Sea, Fisheries Research Agency, 2-17-5 Maruishi, \\ Hatsukaichi, Hiroshima 739-0452, Japan \\ ${ }^{2}$ Research Fellow of the Japan Society for the Promotion of Science
}

Received 19 October 2012; Accepted 28 December 2012

\begin{abstract}
Plate culturing techniques are important in many biological experiments, though plate culturing of diatoms, especially Centrales species, is difficult. In this study, we tested the simple decantation method for dispersing cells on an agar plate with a finely dimpled surface for culturing the Centrales diatom Chaetoceros tenuissimus Meunier. The results showed that $C$. tenuissimus cells uniformly grew on the surface of a dimpled plate according to the pattern of each pocket, using the decantation method. In contrast, only a fraction of the cells survived and made colonies on a smooth-surfaced agar plate, even using the decantation method. Cell growth was not observed on either dimpled or smooth plates when cells were dispersed by daubing using a spreader. Since this new method is easy and inexpensive and cells grow well on the plate, it might be useful for studies on diatom biology.
\end{abstract}

Key words: decantation methods, diatom, patterned agar plate, plate culture

Diatoms are microalgae that play an important role in global carbon fixation. Many researchers have studied diatom biology and ecology using various experimental methods. Agar plate culturing methods for microalgae were developed in the 1950s. Initially, agar plate cultures were used for developing axenic strains of microalgae (Pringshein 1949, Lewin 1959). Plate culturing techniques were also utilized for stress tests on microalgae, e.g. antibiotics and diverse environmental factors (Wright 1975). Recently, complete genome sequences have been reported for two different diatoms, Thalassiosira pseudonana Hasle \& Heimdal (Centrales) and Phaeodactylum tricornutum Bohlin (Pennales) (Armbrust et al. 2004, Bowler et al. 2008). For molecular genetic experiments on diatoms, useful plate culturing methods need to be developed. Pennate diatom species are culturable on agar plates (Lewin 1966), while it is considered difficult to apply these methods to centric species. This is because they have not, in the past, grown well in plate cultures (Iwasaki 1979b). Developing a simple plate culturing method for Centrales is therefore necessary for a wide range of further diatom studies.

In this paper, a simple and easy method of agar plate culturing for centric diatoms is described using the planktonic species Chaetoceros tenuissimus Meunier (Centrales), which has been considered difficult to culture on

\footnotetext{
*Corresponding author: Yuji Tomaru; E-mail, tomaruy@affrc.go.jp
}

regular agar plates. We tested the decantation method using a plate with a dimpled surface and examined cell growth.

Agar plates were prepared with $25 \mathrm{~mL}$ of $1 \%$ agar in modified SWM3 medium enriched with $2 \mathrm{nM} \mathrm{Na} \mathrm{SeO}_{3}$ (Chen et al. 1969, Itoh \& Imai 1987) in a 9-cm plastic petri dish (IWAKI, Tokyo, Japan). Sterilized nylon mesh (NY10-HC, Tanaka Sanjiro Co. Ltd., Fukuoka, Japan) with a diameter of $8.8 \mathrm{~cm}$ was overlaid on normal SWM3 plates. Five mililiters of the same agar media, molten, was poured onto the mesh (Fig. 1A). After solidification, the mesh with extra fixed agar was removed from the agar plate. In this procedure, the nylon mesh created a dimpled surface on the smooth agar plate (Fig. 1B).

Axenic clonal C. tenuissimus strain 2-10 (Shirai et al. 2008), was used for this experiment. Cells were grown in modified SWM3 liquid medium under a 12/12-h light-dark cycle of ca. 110 to $150 \mu \mathrm{mol}$ of photons $\mathrm{m}^{-2} \mathrm{sec}^{-1}$ using cool white fluorescent illumination at $15^{\circ} \mathrm{C}$. The cell growth on the dimpled plate was compared with that on an agar plate with a smooth surface (smooth plate). To spread cells on the plate, the following two methods were employed: 1) a $100-\mu \mathrm{L}$ cell suspension with $10^{5}$ cells $\mathrm{mL}^{-1}$ was put on the agar plate and daubed using a spreader (daubing method), 2) a 5-mL cell suspension with $10^{5}$ cells $\mathrm{mL}^{-1}$ was poured onto agar plates and cultured for $12 \mathrm{~h}$ under the conditions described above and excess 
A

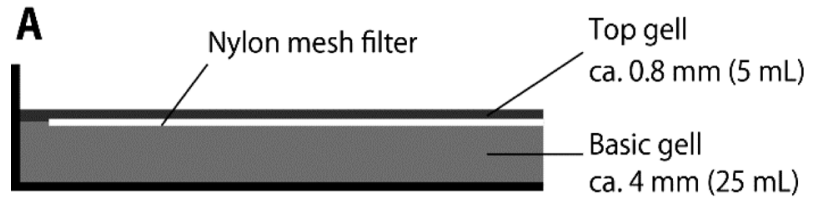

Removing the nylon mesh with top gell

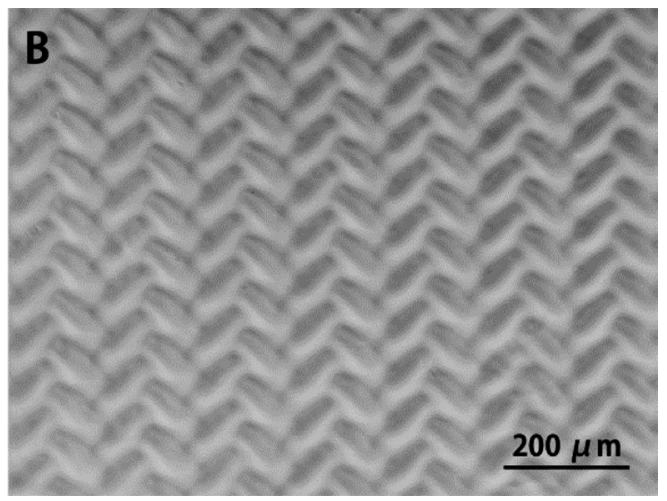

Fig. 1. A. Schematic diagram of a method for preparing agar plates with a dimpled surface. Figures show a cross-section diagram of agar plates. B. Magnified photograph of the surface of the newly developed SWM3 plate. Nylon mesh patterns are printed on the agar plate.

water was fully discarded by decantation (decantation method). All plates were cultured under the conditions described above for 7 days. Cultures were observed by eye and also photographed with a digital camera (D200 with AF-S DX Micro NIKKOR $40 \mathrm{~mm}$ f/2.8G, Nikon, Tokyo, Japan), and highly magnified cells were observed using an inverted microscope (Eclipse Ti-U, Nikon, Tokyo, Japan).

Using the daubing method, no cell colonies were detected on either plate medium (Fig. 2A, B). In contrast, using the decantation method, cell growth was observed on both types of plates (Figs. 2-C-H). Cell colonies were observed after 1 week on the normal plate (Fig. 2-E), and cells grew more uniformly on the patterned plate than on the smooth plate (Fig. 2-F). Similar results were obtained in the replicate experiments (data not shown). These results show that $C$. tenuissimus grew well on agar plates when using the decantation method, and suggests that the daubing method is not suitable for plate culturing of diatoms. For diatoms and other algal species that are difficult to culture on agar plates with the daubing method, spray methods using special instruments have been used (Pringshem 1949). By means of this method, diatom cells might be less damaged relative to those subjected to the daubing method and may be uniformly spread on a plate with sufficient water for their growth.

Microscopic observations revealed that $C$. tenuissimus grew uniformly on the dimpled plate (Fig. 2-F, H). The dimples on the agar surface help maintain adequate hydration, which is required for cell growth. In addition, the cells are easily retained in the dimples, resulting in the uniform cell growth over the plate surface. In contrast, on the smooth-surfaced SWM3 plate, only a fraction of the cells survived and they only made small colonies during the 9 days of culturing (Fig. 2-E, G). Several researchers have tried to establish an easy plate culture method for algae (Iwasaki 1979a, Andersen 2005). They tested various culture media on diverse microalgal species. However, a widely applicable plate culture method for growing algae has not been established. Other studies on algal plate cul-

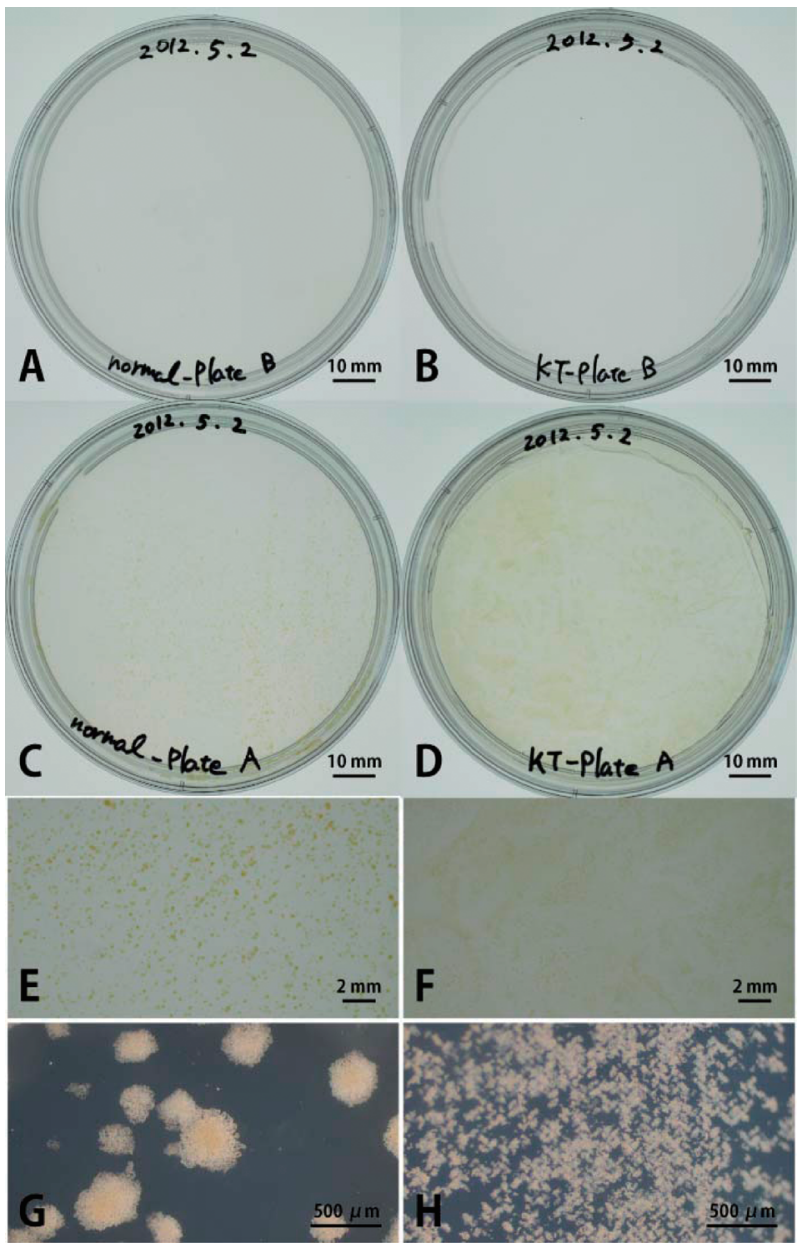

Fig. 2. Photographs of growth patterns of C. tenuissimus on agar plate media. Cultured plate using the spreading method on a normal plate (A) and the patterned plate (B). Cultured plate using the decantation method on the normal plate $(C)$ and the patterned plate (D). $\mathrm{E}$ and $\mathrm{F}$ indicate magnified photographs of the plate surface of $\mathrm{C}$ and $\mathrm{D}$, respectively. $\mathrm{G}$ and $\mathrm{H}$ indicate micrographs of the plate surface of $\mathrm{C}$ and $\mathrm{D}$, respectively. 
ture methods have used soft agar media (Nagasaki \& Imai 1994, Lakeman \& Cattolico 2007). They reported that such media are useful for several algal species, though an important problem is that algal cells are embedded into the low-melting point agar gel. The cell embedding procedure is complex and researchers need experience to use it successfully. Also, the low-melting point agar is expensive. The effect of the shape of the plate's surface was not investigated in previous studies. In this study, we focussed on the utility of a plate medium with a surface of fine pockets. The cell cultures were poured onto a patterned-surface agar plate and the excess culture medium was discarded. Thereafter, the cells retained on the plate surface grew successfully. Therefore, the present method would be much easier and less expensive than the method using soft agar media.

The results of this study showed that $C$. tenuissimus cells, which are difficult to grow on normal plates using conventional methods, were able to survive on a plate medium with fine grooves when seeded using the decantation method. It is possible that this simple and low-cost technique could be applicable to the culture of other Centrales species and other phytoplankters. Recently, we observed that $C$. tenuissimus have a cell-to-cell communication system in spite of them being unicellular species (unpublished data). These uniformly growing cells on agar plates may be particularly useful for cell interaction experiments. The plate culturing method developed in the present study may accelerate studies on diatom and other microalgal biology.

\section{Acknowledgements}

This study was supported by Research Fellowships for Young Scientists and Grants-in-Aid for Young Scientists (A) (22688016) from the Japan Society for the Promotion of Science.

\section{References}

Andersen RA (2005) Algal Culturing Techniques: A Book for
All Phycologists. Elsevier, Oxford, UK, 578 pp.

Armbrust EV, Berges JA, Bowler C, Green BR, Martinez D, Putnam NH, Zhou S, Allen AE, Apt KE, Bechner M et al. (2004) The genome of the diatom Thalassiosira pseudonana: ecology, evolution, and metabolism. Science 306: 79-86.

Bowler C, Allen AE, Badger JH, Grimwood J, Jabbari K, Kuo A, Maheswari U, Martens C, Maumus F, Otillar RP et al. (2008) The Phaeodactylum genome reveals the evolutionary history of diatom genomes. Nature 456: 239-244.

Chen LCM, Edelstein T, McLachlan J (1969) Bonnemaisonia hamifera Hariot in nature and in culture. J Phycol 5: 211-220.

Itoh K, Imai I (1987) Rafido so [Raphidophyceae]. In: A Guide for Studies of Red Tide Organisms. (ed Japan Fisheries Resource Conservation Association). Shuwa, Tokyo, pp. 122130. (in Japanese)

Iwasaki H (1979a) Isolation and culturing of micro algae. In: Methods in phycological studies (eds Nishizawa K, Chihara M) Kyoritsu-Syuppan, Tokyo, pp. 177-189. (in Japanese)

Iwasaki H (1979b) Kinds and elements of culture medium. In: Methods in phycological studies (eds Nishizawa K, Chihara M) Kyoritsu-Syuppan, Tokyo, pp. 281-293. (in Japanese)

Lakeman MB, Cattolico RA (2007) Cryptic diversity in phytoplankton cultures is revealed using a simple plating technique. J Phycol 43: 662-674.

Lewin J (1959) The isolation of algae. Rev Algol 3: 181-197.

Lewin J (1966) Boron as a growth requirement for diatoms. J Phycol 2: 160-163.

Nagasaki K, Imai I (1994) Solid-phase culture of marine phytoflagellates. Bull Jpn Soc Microb Ecol 9: 37-43.

Pringshein EG (1949) Pure Culture of Algae. Cambridge Univ Press, London, 119 pp.

Shirai Y, Tomaru Y, Takao Y, Suzuki H, Nagumo T, Nagasaki K (2008) Isolation and characterization of a single-stranded RNA virus infecting the marine planktonic diatom Chaetoceros tenuissimus Meunier. Appl Environ Microbiol 74: 40224027.

Wright SJL (1975) A simple agar plate method, using microalgae, for herbicide bio-assay or detection. Bull Environ Contam Toxicol 14: 65-70. 